\title{
A POESIA: CORPO, PERFORMANCE E ORALIDADE
}

Dalva de Souza Lobo*

RESUMO: A poesia é sempre um campo frutífero para pensar a arte e sua relevância para a práxis social e, considerando que ela deriva do cotidiano já que implica a relação direta e ativa com o outro, a proposta do presente ensaio é refletir sobre a poesia na perspectiva da performance da vococorporal, aqui compreendida como signo sonoro e social que tem no corpo do poeta/performer seu devir. Dessa forma, busca-se examinar como a noção de início, meio e fim preestabelecidos pela taxonomia linguística cede lugar à experimentação levando a uma poética cuja fruição se constrói pela não linearidade, possibilitando, assim, a criação de novas ambiências signicas nas quais o fazer e o abstrair tornam-se sinônimos. Outro ponto importante para essa reflexão é a relação entre o fazer poético e a memória, tendo em vista a característica desta última de não linearidade e de atualização de eventos na presentidade da performance, a qual, por sua vez, remete ao engajamento corporal do poeta, seja na perspectiva do som, seja na perspectiva do silêncio. Para examinar tais aspectos, o presente ensaio apoia-se em autores relevantes para discutir voz e memória como Henri Bergson e Paul Zumthor. No que concerne aos conceitos performance e experimentação, privilegiou-se Renato Cohen, Philadelpho Menezes entre outros. Dessa forma, o resultado pretendido e sempre provisório, como deve ser toda consideração relativa à reflexão sobre poética, visa redimensionar o que compreendemos como performance poética em sua expansão signica.

PALAVRAS-CHAVE: Voz. Performance. Memória. Ambiência.

\section{ORALIDADE E PERFORMANCE}

$\mathrm{Na}$ oralidade, a linguagem poética implica sincronia entre corpo e voz na criação de um instante que convida o interlocutor a uma participação mais efetiva. Nesse sentido, a percepção sensorial e estética leva à jouissance, isto é, ao fruir estético.

Esse efeito teatral assemelha-se ao mousikè, que designa "ao mesmo tempo a dança, a música, vocal e instrumental, as estruturas métricas do poema e a prosódia da palavra". (ZUMTHOR, 2005, p. 147).

A presentidade da voz no instante da performance promove o fruir, devido à subjetividade que é expressa pelo locutor através das energias vocal e corporal, tal qual um ritual a concretizar e atualizar um evento passado. Tanto locutor quanto interlocutor são envolvidos pela dramatização implicada na performance, isto é, pela

\footnotetext{
* Universidade Federal de Lavras, Lavras, Minas Gerais, Brasil. Imeio: dalvalobo@terra.com.br 
duração e pelo espaço que lhe são próprios, e que são apresentados como presentidade.

A dimensão dialógica entre voz, tempo, espaço e corpo evoca as memórias mais remotas nas quais as sensações armazenadas se pluralizam e se ampliam, adquirindo novos contornos em função da percepção que cada evento estabelece.

Não são mais os cinco sentidos fragmentados pelas ciências biológicas, mas o conjunto de percepções em torno de cada um deles que se volta para a unidade cognitiva que a performance faz despertar tanto no executante quanto no público.

$\mathrm{Na}$ poesia oral, a voz assume sua condição de escritura plena, na qual corpo e memória se articulam integrando, por vezes, fala e escrita materializadas na sonoridade de uma linguagem que exprime um pensamento tão heteróclito quanto ela.

Ambos, performer e interlocutor, ademais das sensações que todos têm, são levados pelas lembranças surgidas através das redes mnemônicas que a performance desperta e que os constituem. Assim, a lembrança, antes virtualizada na memória, é atualizada como linguagem do e no corpo.

Assim, a performance leva o interlocutor a experimentar novas percepções do signo poético, devido à hipercodificação. E essas percepções podem chegar a modificar o conhecimento:

Toda poesia atravessa e integra, mais ou menos imperfeitamente, a cadeia epistemológica sensação-percepção-conhecimento-domínio do mundo: a sensorialidade se conquista no sensível para permitir, em última instância, a busca do objeto. Ora, todo conhecimento está a serviço do vivo, a quem ele permite preservar no seu ser. Por isso, a cadeia epistemológica continua a fazer do vivente um sujeito; ela coloca o sujeito no mundo. (ZUMTHOR, 2007, p. 81). 
Diferentemente do happennig ${ }^{1}$, arte de improviso na qual interessa mais o processo do que o resultado, a performance demanda preparação, isto é, ela deve ser elaborada, embora se situe na fronteira das convenções, escapando às delimitações deste.

Ela percorre espaços alternativos e transita entre artes plásticas e cênicas, o que lhe confere a possibilidade de harmonizar música, poesia, oralidade, dança etc., para formalizar seu ritual.

A arte performática cria outros recortes epistemológicos, impondo sua marca ao acontecimento vivo em que ocorre a comunicação poética.

\begin{abstract}
A arte da performance, liberando o instante à vertigem da emergência de Universos ao mesmo tempo estranhos e familiares, tem o mérito de levar ao extremo as implicações dessa extração de dimensões intensivas. (...) nos evidencia a gênese do ser e das formas antes que elas tomem seu lugar nas redundâncias dominantes com a dos estilos, das escolas, das tradições da modernidade. (GUATTARI, 2008, p. 114).
\end{abstract}

A performance pode, então, desconstruir ${ }^{2}$ qualquer estrutura linear que a ela se associe, e se redescobre na voz, tornando a comunicação poética um corpo sem órgãos ${ }^{3}$, no qual a experimentação dos signos em devir é constantemente atualizada.

Um resultado dessa performance é a integração de suas vozes com os sons do cotidiano produzindo uma forma de arte global em que os elementos significantes são dados pela circunstância do momento, concebendo uma entropia positiva, ou ruído, no sentido artístico dado a essa palavra por Luigi Russolo.

\footnotetext{
${ }^{1}$ Idealizado pelo artista plástico e performer Allan Kaprow, o happening é um evento artístico baseado no improviso e na imprevisibilidade. No happening, o limite entre o ficcional e o real é muito tênue e, nesse sentido, a convenção que sustenta a representação é constantemente rompida. Esta ruptura se dá de várias formas, como pelas situações de imprevisto - o público não sabendo o que vai acontecer - e nesse sentido entrando em "situações de vida" em que pode ser instado a participar a qualquer instante. (COHEN, 2007, p.133).

${ }^{2}$ No sentido derrideano mesmo!

${ }^{3}$ Corpo sem órgãos, ou CsO, é um conceito criado pelos filósofos Gilles Deleuze e Félix Guattari (1996): "um CsO é o campo de imanência do desejo, o plano de consistência própria do desejo (ali onde o desejo se define como processo de produção, sem referência a qualquer instância exterior, falta que viria a torná-lo oco, prazer que viria a preenchê-lo". ( p.15).
} 
Em Arte dos ruídos, documento conhecido também como O Manifesto dos Ruídos, publicado em 1913, Russolo aponta para a dissonância de sons que resultam no ruído enquanto expressão artística e para sua influência sobre a voz, visto que, ao falar, administramos os sons de nossa articulação simultaneamente aos diferentes graus de ruído externo.

Fig. 1 - Manifesto do ruído, de Luigi Russolo.

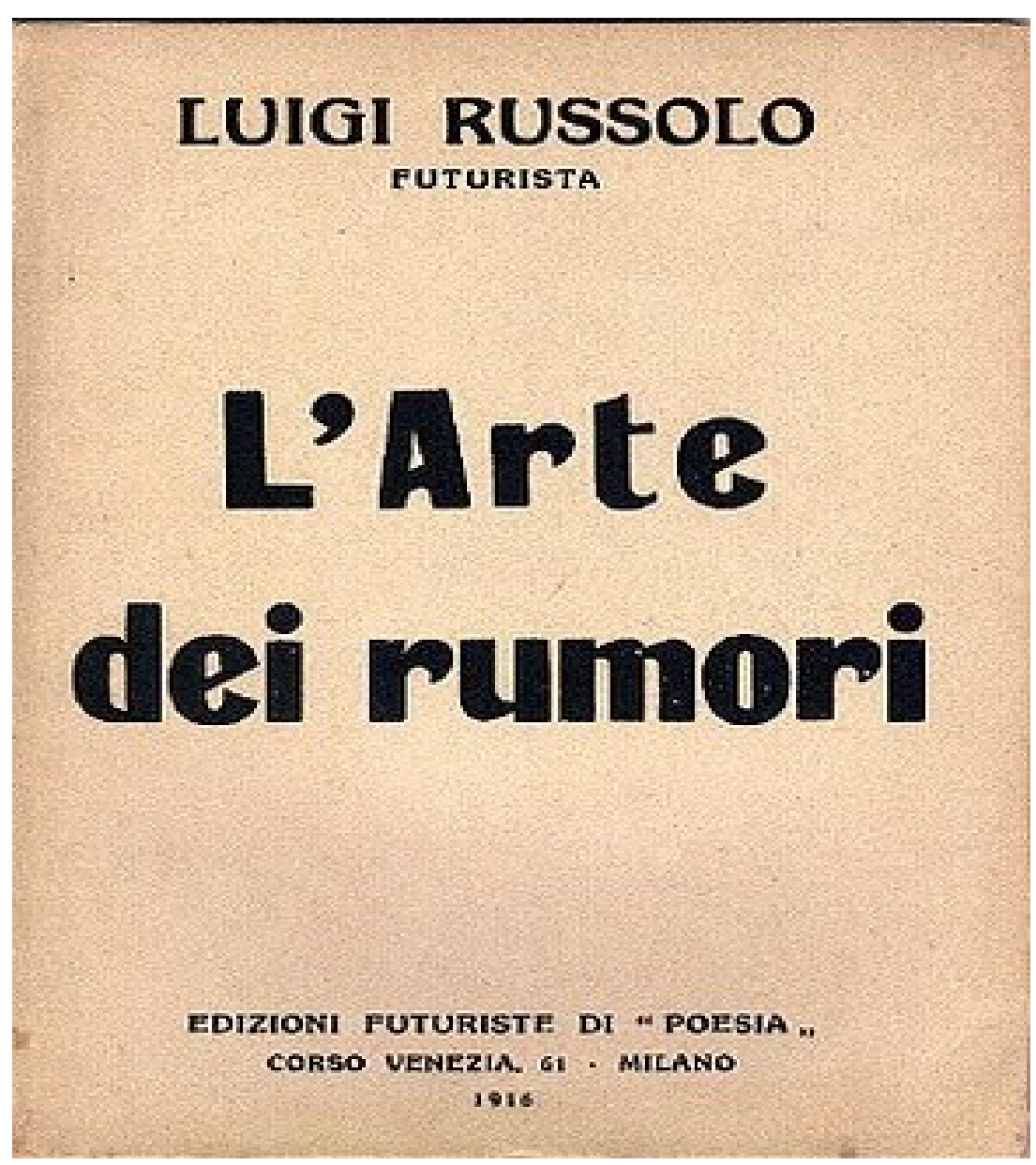

Fonte: <http://www.twitteringmachines.com/2008/03/>.

A pretensão do poeta era harmonizar tantos ruídos quanto possível, conforme mencionou ao amigo, também poeta futurista, Ballila Pratella (2009): "Nós queremos entoar e regular harmônica e ritmicamente estes variadíssimos ruídos. O ruído é, portanto, familiar a nosso ouvido, e tem o poder de nos remeter imediatamente à vida mesma". (RUSSOLO apud MENEZES, 2009, p. 54). 
Em seu Manifesto do Ruído, o poeta menciona seis famílias de ruídos, propondo uma inovação para a orquestra futurista que, dadas as combinações mais esdrúxulas e variadas, tornava a linguagem poética tão irregular quanto a vida.

1. Estrondos, trovões, explosões, rajadas de sons, quedas, ribombos;

2. Silvos, sibilos, sopros;

3. Cochichos, murmúrios, sussurros, cicios, borbotões;

4. Rangidos, estalidos, roçaduras, zumbidos, crepitações, fricções;

5. Ruídos obtidos com percussão sobre metais, madeiras, peles, pedras, terracotas, etc;

6. Vozes de animais e de homens, gritos, berros, gemidos, bramidos, risadas, estertores, soluços. (IBIDEM, p. 54)

A partir dessa classificação, a sensibilidade musical se multiplica, oferecendo novas possibilidades de experimentação para o som que percorreu a composição poética, conferindo-Ihe novas texturas mediante a integração da voz com os demais sons e ruídos.

O processo da criação poética evidenciará os mais diversos e inusitados tipos de sons, como os de máquinas, buzinas, além dos sons da natureza, como raios, trovões, etc.

A essa diversidade sonora somava-se um corpo destituído de forma, o corpo performatizador de novas linguagens, como já anunciara Marinetti (2005) em seu Manifesto do Futurismo. Deste, aliás, é oportuno evidenciarmos mais alguns aspectos que apontam para a performance corporal substancialmente ligada à linguagem poética:

4. Nós declaramos que o esplendor do mundo se enriqueceu com uma beleza nova: a beleza da velocidade. Um automóvel de corrida com seu cofre adornado de grossos tubos como serpentes de fôlego explosivo... um automóvel rugidor, que parece correr sobre a metralha, é mais belo que a Vitória de Somotrácia.

6. É preciso que o poeta se desgaste com calor, brilho e prodigalidade, para aumentar o fervor entusiástico dos elementos primordiais. 
7. Não há beleza senão na luta. Nada de obra-prima sem um caráter agressivo. A poesia deve ser um assalto violento contra as forças desconhecidas para intimidá-las a deitar-se diante do homem

11. Nós cantaremos as grandes multidões movimentadas pelo trabalho, pelo prazer u pela revolta; as marés multicoloridas e polifônicas das revoluções nas capitais modernas; a vibração noturna dos arsenais e dos estaleiros sob suas violentas luas elétricas; as estações glutonas comedoras de serpentes que fumam; as usinas suspensas nas nuvens pelos barbantes de suas fumaças; as pontes para pulos de ginastas lançadas sobre a cutelaria diabólica dos rios ensolarados; os navios aventureiros farejando o horizonte; as locomotivas de grande peito, que escoucinham os trilhos, como enormes cavalos de aço freados por longos tubos, e o voo deslizante dos aeroplanos cuja hélice tem os estalos da bandeira e os aplausos da multidão entusiasta. (MARINETTI apud TELES, p.91)

Liberar o corpo implica a libertação da palavra, revelando sua movência como registro vivo. De outro lado, a abolição da sintaxe pode resultar numa intertextualidade prosódica ${ }^{4}$, o que vai permitir lançar um novo olhar sobre a escritura poética advinda da performance.

O que os poetas instituíram como sons são recursos da natureza que inovam o fazer poético, e isso nos remete ao pensamento de Barthes (2004) sobre a poesia. Segundo ele, a palavra "explode acima de uma linha de relações esvaziadas, a gramática fica desprovida de sua finalidade, torna-se prosódia, não é mais do que uma inflexão que dura para apresentar a Palavra" (p. 41). Nesse aspecto, ela, a palavra, é redescoberta como energia.

Um ponto importante nesse movimento é a relação entre o som e o silêncio - eles estão em constante desdobramento de presença e ausência, dialogando com o fazer poético. É como quando imaginamos ou testemunhamos uma cena de um poeta vocalizando sua criação. Nela, nessa cena, reconstruímos sentidos provocados pelos ruídos e pelos silêncios; ela é enunciada como um hic et nunc repleto de possibilidades de recriação: como disse o músico John Cage (1985), "nenhum som teme o silêncio que o extingue. E nenhum silêncio existe que não esteja grávido de sons" (CAGE, 1985, p. 98).

\footnotetext{
${ }^{4}$ Esse conceito está mais claramente formulado em um trabalho ainda inédito: Meditações sonoras em Catatau: o texto amplificado. Tese de doutoramento. Universidade Presbiteriana Mackenzie, 2012.
}

Texto Digital, Florianópolis, Santa Catarina, Brasil, v. 11, n. 1, p. 194-208, jan./jun. 2015. ISSNe: 1807-9288. 
Como pulsões intermitentes, os sons se definem a partir de um não-som, isto é, daquilo que supomos como silêncio tendo em vista a não propagação no ar. No entanto, é no hiato entre ambos que nossos sentidos atravessam, e nossa voz, nossa percepção se animam numa vontade de criação.

Para Zumthor (2007),

a voz repousa no silêncio do corpo. Ela emana dele, depois volta, mas o silêncio pode ser duplo; ele é ambíguo: absoluto, é um nada; integrado ao jogo da voz, torna-se significante: não necessariamente tanto como signo, mas entra no processo de significância (p. 85).

Esse deslocamento constante cria paisagens sonoras onde o corpo sem órgãos irrompe da voz como energia, produzindo outros significados para a linguagem poética (e se trata de significados cada vez mais dissociados da necessidade de um significante materializado).

\section{LINGUAGEM POÉTICA E SONORIDADE - HORIZONTES DO PROVÁVEL}

Voltando nosso olhar para as vanguardas do início do século $\mathrm{XX}$, percebemos que o desenvolvimento do som levou a outras formas de manifestação, quando passou a admitir sons inabituais aos ouvidos humanos.

A partir do Manifesto dos Ruídos, de Luigi Russolo, o ruído sonoro passou a orquestrar as relações, bem como a linguagem poética, tal como ele a concebia e, nesse sentido, pensar o ruído na poesia implica reconhecer sua condição de composição instauradora de novas percepções que ultrapassam a repetição e a linearidade temporal.

O ruído faz parte da vida, interferindo, inclusive, na voz, cuja altura regulamos de acordo com os sons ou ruídos ambientes. A dissonância enriquece a expressão sonora, ultrapassando o purismo pretendido pela musicalidade enquanto som puro e 
melodioso como ocorreu com o canto gregoriano, por exemplo, que, apesar de belíssimo, era quase uníssono.

Vemos que a melodia pode se tornar, em certa medida, asséptica, por fechar-se em si mesma, quase como se ocorresse de forma independente e estranha à vida e ao cotidiano, como fora no passado, nas ocasiões em que era atribuída aos deuses: "O som foi considerado como sagrado e reservado aos sacerdotes, que dele se serviram para enriquecer os seus ritos. Nasceu assim a concepção do som como coisa em si, distinta e independente da vida" (RUSSOLO apud MENEZES, 2009, p. 52).

Com o tempo, a dimensão sagrada do som cedeu lugar à procura de novos acordes que trouxessem a harmonia entre diversos sons, mas harmonia que não se deixa confundir com melodia.

Hoje, vemos que o ruído, harmonizado à vida, contempla as heterogeneidades. Com isso, a composição sonora pode revelar-se repleta de arritmias e instabilidades muitas vezes estranhas ao contexto linguístico, mas absolutamente viáveis quando se trata de linguagem poética, pois a desarticulação ou o estranhamento causado pelo ruído são paradigmas de criação de novos signos. Por isso, escutar, ao contrário de ouvir, requer atenção, visto que o fenômeno sonoro se compõe de vozes, ruídos e silêncios, instâncias de presença e de ausência.

O que provoca o ruído e desestabiliza a linguagem do cotidiano tem a ver com o fato de o som ser intersemiótico na medida em que pluraliza e descentra as perspectivas habituais. Além disso, trata-se de um signo que carrega significados potenciais para além da redundância prevista por um código orbitando um sistema de leis que regem os signos em sua formação simbólica de forma arbitrária.

$\mathrm{Na}$ arte, isso implica a desordenação de um sistema linear e previsível com o qual ela rompe, tornando-se elemento criativo ou organismo vivo que remete a inúmeras possibilidades de experimentação poética. 
O ruído nos remete à vida mesma, ao cotidiano, haja vista os trovões, sibilos e outras formas de som consideradas irregulares em relação ao som melodioso, mas muito utilizadas pelos poetas futuristas que buscavam, através dos experimentos, a inovação da linguagem poética:

\begin{abstract}
É preciso que se rompa com este círculo restrito de sons puros e que se conquiste a variedade infinita de "sons-ruído". Nós futuristas amamos e degustamos, todos, profundamente as harmonias dos grandes mestres. Beethoven e Wagner nos sacudiram os nervos e o coração por muitos anos. "Por ora estamos fartos disto e temos muito mais prazer em combinar idealmente os ruídos de trem, de motores de explosão, de vagões e de multidões clamorosas, do que em re-ouvir, por exemplo, a Heróica ou a Pastoral." (MENEZES, 2009, p. 52-53)
\end{abstract}

As poéticas pautadas no horizonte do provável têm como expoentes artistas plásticos, poetas e músicos, dentre os quais Kurt Schwitters, entre outros que foram responsáveis pelo salto qualitativo na performance da voz, associando-a e integrando-a a outros sons e ruídos, tanto os da natureza quanto os instrumentais.

Cada vez mais agregados às linguagens não vinculadas ao registro da escrita fixa, esses artistas efetivaram em sua composição a produção ruidosa como entropia positiva do fazer poético, atestando que a vida, assim como a arte, é habitada por som e silêncio, ruído e silêncio. Nisso reside sua poesia.

Para Schwitters, a arte deveria ser interdisciplinar, conjugada em todas as suas formas de expressão, como escultura, pintura e poesia. Esta última deveria utilizar qualquer material disponível, como ferros velhos, restos de anúncios, citações, entre outros, visando a uma linguagem poética dissociada do lugar comum das convenções linguísticas, sociais e estéticas daquele momento.

A inovação, assim, consistia numa espécie de bricolage que operava artesanalmente os objetos encontrados, que eram então organizados e reorganizados em vários contextos e despidos de categorias preestabelecidas. Para Schwitters, era necessário que houvesse, então, 
despejo linguístico - esse amontoado residual de frases feitas, locuções dessoradas, ecos memorizados de anúncios, citações, convenções sentimentais, expressões de etiquetas. Também assumia o aspecto de um material a ser reencontrado e devolvido ao mundo novo do poema. (CAMPOS, 1977, P. 36)

A essa nova estética ele denominou de arte MERZ, sílaba da palavra KOMMERZ, retirada do anúncio KOMMERZ UND PRIVAT BANK, e que passou a caracterizarse, após a dissociação silábica, como forma abstrata, conforme justificava:

Dei à minha nova maneira, fundada no princípio do emprego desses materiais, o nome de MERZ, tirada da segunda sílaba da palavra KOMMERZ. Esse nome nasceu em um quadro, uma imagem sobre a qual se podia ler, recortada de um anúncio do KOMMERZ UND PRIVAT BANK, e colada entre formas abstratas, a palavra MERZ. (CAMPOS, 1977, p. 36 ).

Fig. 2 - Arte MERZ by Kurt Schwitters.

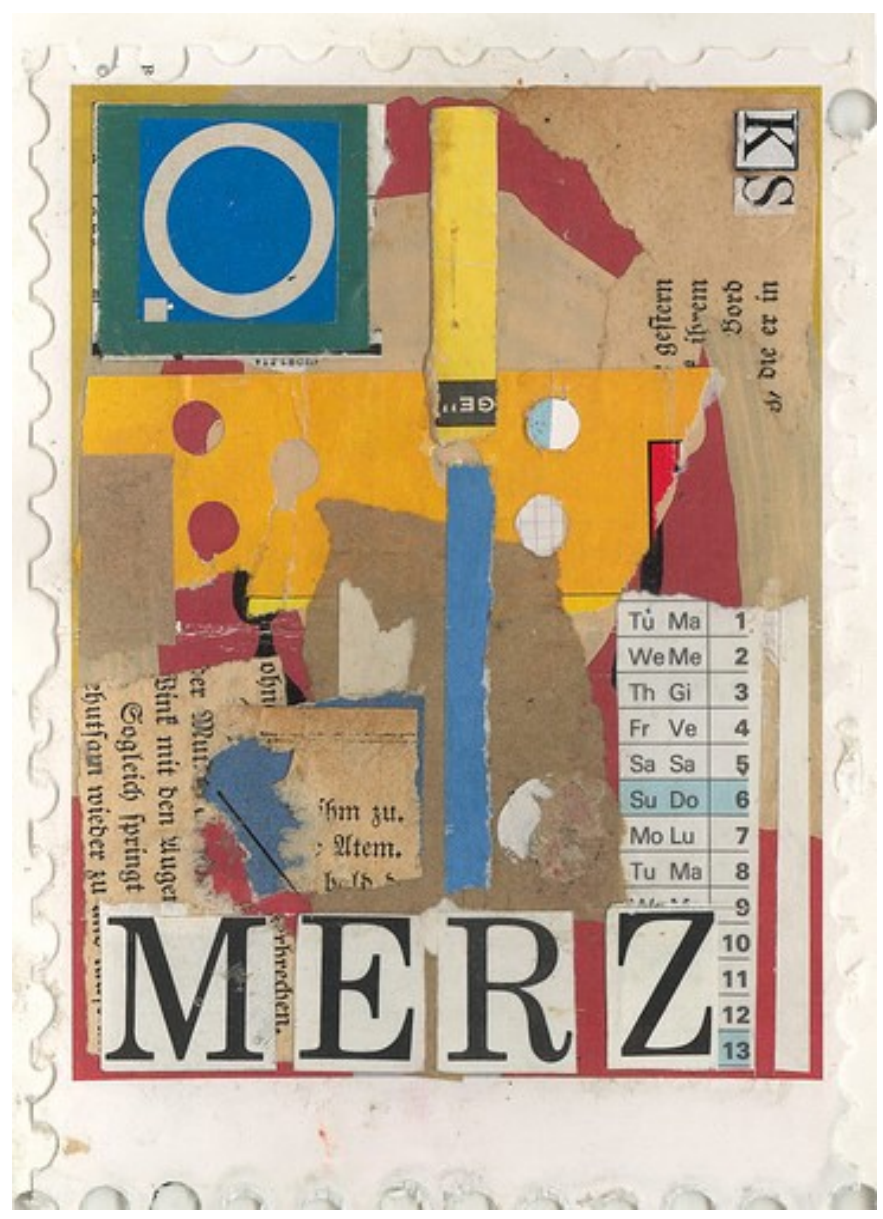

Fonte: <http://dadoacaso.blogspot.com/2011/04/kurt-schwitters-o-dada-alemao-i-por.html>

Texto Digital, Florianópolis, Santa Catarina, Brasil, v. 11, n. 1, p. 194-208, jan./jun. 2015. ISSNe: 1807-9288. 
O efeito visual de tal composição poética deveria estender-se à sonoridade, e, para tanto, Schwitters harmonizava palavras, sílabas e letras em poemas, não de forma convencional, pautada por onomatopeias, mas de forma a produzir ruídos, para ele, verdadeiras experiências sonoras.

Potencializadas pela voz de um solista, as possíveis variações de tonalidades, somadas às oscilações como gagueira, hiatos entre uma respiração e outra, além de outros recursos, apontavam para uma possível plenitude da arte.

De fato, a preocupação do poeta era redescobrir os sons primordiais, ou seja, os sons anteriores às significações, isto é, anteriores às palavras verbalmente constituídas e sistematizadas. Para tanto, contava com a performance oral:

\begin{abstract}
Em seu poema URSONATE ou Sonata Primordial, publicado pela revista Merz 24, entre 1921 e 1932, é evidente sua intenção de transformar unidades sonoras em signos, como apontam os fragmentos publicados pela revista Revue de la poésie, n. 3. "Scherzo der Ursonate lanke tr gl" ou "Scherzo da Sonata Primordial lanke tr gl". Segundo o designer e fotógrafo Moholy-Nagy, amigo de Kurt Schwitters, Ursonate é uma composição de 35 minutos de duração, composto de quatro movimentos, um prelúdio e uma cadência no último deles. (CAMPOS, 1977, p. 44).
\end{abstract}

A linguagem imaginária do poema era constituída por palavras, sílabas dispostas de forma a formar blocos de sons sem qualquer significado lexical. Sua coerência se fazia pela sonoridade.

A adequação da estrutura musical à expressão de signo verbal escrito resultou numa linguagem sem língua específica, podendo pertencer a qualquer uma ou a nenhuma, em um contexto cuja lógica advinha do emocional, algo próximo da linguagem Zaum, conforme podemos observar nos fragmentos da música-poema composta por Schwitters, Ursonate: 
Introducción:

Fümms bö wö tää zää Uu,

$$
\text { pögiff, }
$$

kwii Ee.

O00000000000000000000000,

dll rrrrr beeeee bö

dll rrrrr beeeee bö fümms bö,

(A)

rrrrr beeeee bö fümms bö wö, beeeee bö fümms bö wö tää,

bö fümms bö wö tää zää,

fümms bö wö tää zää Uu:

primeira parte:

tema 1:

Fümms bö wö tää zää Uu,

$$
\text { pögiff, }
$$

Kwii Ee.

tema 2:

Dedesnn nn rrrrr,

li Ee,

mpiff tillff too,

tillil,

Jüü Kaa?

tema 3:

Rinnzekete bee bee nnz krr müü? 


\section{ziiuu ennze, ziiuu rinnzkrrmüü,}

rakete bee bee,

tema 4

\section{Rrummpff tillff toooo?}

exposición:

\section{Ziiuu ennze ziiuu nnzkrrmüü,}

\section{Ziiuu ennze ziiuu rinnzkrrmüü}

rakete bee bee? rakete bee zee.

Fonte: <http://www.ubu.com/historical/schwitters/ursonate.html>

As peças que compunham o concerto foram constituídas a partir da desorganização do ponto de vista lexical e sintático, e as palavras dispostas no poema propunham novas leituras a partir da sonoridade, remetendo, nesse sentido, à linguagem verbivocovisual do Finnegans Wake joyciano, ao menos no que concerne à sonoridade e à disposição aleatória das palavras.

O que captamos das leituras dos poemas de Schwitters são as sutilezas nas quais a performance aprofunda os laços entre o homem e o universo. À medida que permite ao discurso poético inúmeras experimentações, leva ao reconhecimento o signo da voz, no qual habitam o som, o silêncio, o ruído e o corpo, sem que haja regras preestabelecidas.

Tomada pela presentidade e pelo efêmero, levando do virtual ao concreto, a performance realiza as experiências que atam, em nosso corpo e memória, os sentimentos e sentidos mais profundos e, dessa forma, atualiza a complexidade de signos que nos constituem.

Assim, as inúmeras experimentações poéticas se rizomatizam, ultrapassando a mesmice do código de tradição linguística e a noção de leitura pré-progamada pelo noção de início meio e fim lineares à medida que a voz em performance dialoga com 
as mais variadas formas de arte. Especialmente em relação ao texto poético oral, notamos o quanto a tessitura dos signos tramam os fios desse diálogo.

\section{Na trama dos fios, alguma consideração.}

Pensando a poesia na perspectiva do engajamento voco-corporal e memorial, notamos como a tessitura oral, viabilizada pela experimentação de sons outros que não os da ordem da taxonomia linguística segue em direção à movência sígnica na qual se hipercodificam voz, som, memória, silêncio, ruído e corpo.

Assim, a performance da voz dilata os laços temporais atualizando-os cronotopicamente na medida em que encontra linhas de fuga a partir das quais novas produções de subjetividade se entrelaçam conduzindo à poeticidade que confirma ser a voz um signo sonoro e social que ultrapassa a taxonomia linguística. Nesse sentido, a noção de um sistema preestabelecido por um código se coloca como um sistema aberto ao pensamento e a cultura do outro, cuja sintaxe se rizomatiza mediante a possibilidade de novas experimentações.

Depreende-se, então, que a poesia tomada no sentido de sua hipercodificação leva ao diálogo e, nessa perspectiva, expande-se para outras ambiências signicas nas quais o fazer e o abstrair interseccionam-se de forma interdisciplinar e com outras manifestações, alargando, assim nossos sentidos e lançando novos recortes epistemológicos sobre a escritura poética.

\section{POETRY: BODY, PERFORMANCE AND ORALITY}

ABSTRACT: Poetry is always a productive field to think about art and its relevance to the social praxis. Considering that it derives from everyday life, since it involves the direct and active relationship with the other, the purpose of this paper is to reflect on poetry from the perspective of vocal-body performance. The vocal-boby performance is understood as an social and sound sign that finds its becoming in the body of the poet/performer. Thus, we seek to examine how the notion of beginning, middle and end, predetermined by linguistic taxonomy, gives way to experimentation, leading to a poetic whose enjoyment is built by the nonlinearity and enables the creation of new signic ambiences where creating and abstracting become synonymous. Another important issue for our reflection is the relationship between poetic construction and memory, considering that this latter is characterized by its nonlinearity and its capacity of updating events in the same presentness of performance which, on the other hand, refers to the engagement of the poet through his/her body, either in sound or in 
silence. In order to examine some of the aspects mentioned above, this paper draws on Henri Bergson and Paul Zumthor to discuss voice and memory. Regarding performance and experimentation concepts, we focused on Renato Cohen and Philadelpho Menezes, among others. Therefore, the intended and always transitory reflection on poetic, as it should be every consideration of this kind, aims to redefine what we mean by poetic performance in its signic expansion.

KEYWORDS: Voice. Performance. Memory. Ambience.

\section{Referências}

BARTHES, Roland. O grau zero da escrita: seguido de novos ensaios críticos. Trad. Mario Laranjeira. São Paulo: Martins Fontes, 2004. (Coleção Roland Barthes).

O grão da voz. Trad. Mário Laranjeira. São Paulo: Martins Fontes, 2004. (Coleção Roland Barthes).

CAGE, John. De Segunda a um ano. Novas Conferências e Escritos de John Cage. Trad. Rogério Duprat. Revisão Augusto de Campos. São Paulo: Hucitec, 1985.

CAMPOS, Haroldo. A Arte no horizonte do provável. São Paulo: Perspectiva, 1977.

COHEN, R. Performance como linguagem. São Paulo: Perspectiva, 2007.

GUATTARI, Félix. Caosmose: um novo paradigma estético. Trad. Ana Lúcia de Oliveira e Lúcia Cláudia Leão. São Paulo: Ed. 34, 2008.

MENEZES, Philadelpho. (Org.) Poesia sonora: poéticas experimentais da voz no século XX. São Paulo: EDUC, 1992.

MENEZES, Flo (Org.). Música eletroacústica: história e estéticas. São Paulo: EDUSP, 2009.

TELES, Gilberto Mendonça. Vanguarda Européia e Modernismo Brasileiro. Apresentação dos principais poemas, manifestos, prefácios e conferências vanguardistas, de 1857 a 1972. Petrópolis, RJ: Vozes, 2005.

ZUMTHOR, Paul. Escritura e Nomadismo: entrevistas e ensaios. Trad. Jerusa Pires Ferreira, Sônia Queiroz. Cotia, SP: Ateliê Editorial, 2005.

Performance, recepção, leitura. Trad. Jerusa Pires Ferreira, Suely Fenerich. São Paulo: Cosac Naify, 2007. 